\title{
Amycolatopsins A-C: antimycobacterial glycosylated polyketide macrolides from the Australian soil Amycolatopsis sp. MST-108494
}

\author{
Zeinab G Khalil ${ }^{1,2}$, Angela A Salim ${ }^{1}$, Daniel Vuong ${ }^{3}$, Andrew Crombie ${ }^{3}$, Ernest Lacey ${ }^{3}$, Antje Blumenthal ${ }^{2}$ \\ and Robert J Capon ${ }^{1}$
}

A southern Australian soil isolate, Amycolatopsis sp. MST-108494, was subjected to a panel of fermentation and media optimization trials, supported by analytical chemical profiling, to detect and enhance production of a rare class of secondary metabolites. Chemical fractionation of two complementary fermentations yielded three new polyketides, identified by detailed spectroscopic analysis as the glycosylated macrolactones, amycolatopsins A (1), B (2) and C (3), closely related to the ammocidins and apoptolidins. Amycolatopsins 1 and 3 selectively inhibited growth of Mycobacterium bovis (BCG) and Mycobacterium tuberculosis (H37Rv) when compared with other Gram-positive or Gram-negative bacteria, with 3 exhibiting low levels of cytotoxicity toward mammalian cells. Thus, our data reveal promising structure activity relationship correlations where the antimycobacterial properties of amycolatopsins are enhanced by hydroxylation of the 6-Me (that is, 1 and 3), whereas mammalian cytotoxicity is decreased by hydrolysis of the disaccharide moiety (that is, 3 ).

The Journal of Antibiotics (2017) 70, 1097-1103; doi:10.1038/ja.2017.119; published online 25 October 2017

\section{INTRODUCTION}

Tuberculosis (TB) is one of the oldest recorded human infectious diseases and, despite much effort and investment, remains one of the most serious globally significant communicable diseases. ${ }^{1}$ Existing frontline treatment for active TB includes the antibiotics isoniazid, rifampicin, pyrazinamide and ethambutol, all of which were introduced into clinical practice $>40$ years ago. Standard therapy for drugsensitive TB involves prolonged treatment ( $>6$ months) with combinations of these vintage antibiotics, most of which exhibit toxic side effects and are compromised in the face of multidrug-resistant TB. With an estimated half a million new cases of multidrug-resistant $\mathrm{TB}$ annually, and the emergence of extensively and totally drugresistant Mycobacterium tuberculosis strains, there is an urgent need for new TB antibiotics. ${ }^{2,3}$

Responding to this challenge, and as an extension of our investigations into the chemistry of Australian microbial biodiversity, we screened libraries of microbial extracts and purified metabolites for growth inhibitory activity against Mycobacterium bovis (BCG), as a laboratory surrogate of $M$. tuberculosis. These studies detected significant growth inhibitory activity against mycobacteria from a rare class of metabolites isolated from Amycolatopsis sp. MST-108494. A detailed investigation of these metabolites identified them as amycolatopsins A (1), B (2) and C (3) (Figure 1), new analogs of the rare apoptolidin and ammocidin structure class. ${ }^{4-7}$ An account of the fermentation, extraction, isolation, structure elucidation and biological properties of $\mathbf{1 - 3}$ is presented below.

\section{RESULTS AND DISCUSSION}

Amycolatopsis sp. MST-108494, a strain closely related to Amycolatopsis magusensis (see Supplementary Information), was isolated from soil collected in 1996 from the rural outskirts of Port Augusta, South Australia. Fermentation of MST-108494 on yeast glucose malt agar (I2A) yielded an extract with HPLC diode-array detection (HPLC$\mathrm{DAD}$ ) profile (Supplementary Figure S3) unique in our database of 300000 actinomycetes, including 2500 actinomycetes type species and 40 Amycolatopsis isolates. In particular, the I2A cultivation featured low-level production of metabolites with UV-visible spectra (DAD, $\left.\lambda_{\max } 278,322\right)$ unprecedented in our databases. Optimization studies in a wide range of media identified beef extract agar (LUA) as optimal for the production of these metabolites, with solvent extraction and reversed-phase preparative HPLC fractionation of a large-scale fermentation yielding $\mathbf{1}$ and 2 . In subsequent analysis of antimycobacterial activity, 1 and 2 exhibited promising (>99\%) growth inhibitory activity. In an effort to obtain additional analogs, we used a modified LUA media, GYA (LUA supplemented with starch), to produce and isolate the related minor metabolite 3.

High-resolution electrospray ionization MS (HRESI(+)MS) analysis of 1 returned a sodium adduct ion consistent with a molecular formula $\left(\mathrm{C}_{60} \mathrm{H}_{98} \mathrm{O}_{23}, \Delta \mathrm{mmu}+1.1\right)$ requiring 12 double bond

\footnotetext{
${ }^{1}$ Institute for Molecular Bioscience, The University of Queensland, St Lucia, QLD, Australia; ${ }^{2}$ The University of Queensland Diamantina Institute, The University of Queensland, Brisbane, QLD, Australia and ${ }^{3}$ Microbial Screening Technologies, Smithfield, NSW, Australia

Correspondence: Professor RJ Capon, Institute for Molecular Bioscience, The University of Queensland, 306 Carmody Road, St Lucia, Queensland 4072, Australia.

E-mail: r.capon@uq.edu.au

Received 20 July 2017; revised 25 August 2017; accepted 4 September 2017; published online 25 October 2017
} 


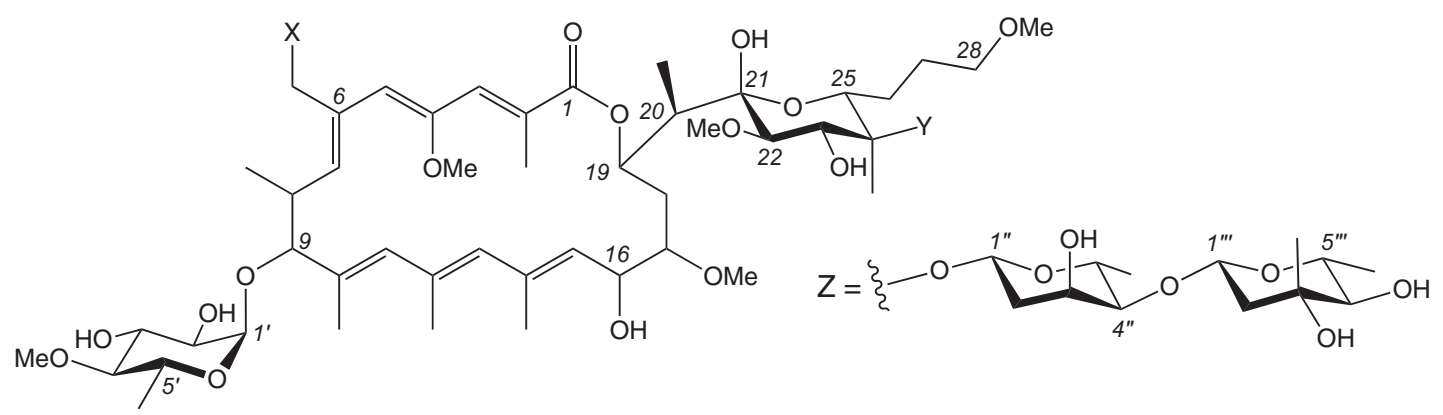

amycolatopsin $\mathrm{A}(1) \mathrm{X}=\mathrm{OH}, \mathrm{Y}=\mathrm{Z}$ amycolatopsin $\mathrm{B}(2) \mathrm{X}=\mathrm{H}, \mathrm{Y}=\mathrm{Z}$ amycolatopsin $\mathrm{C}(\mathbf{3}) \mathrm{X}=\mathrm{OH}, \mathrm{Y}=\mathrm{H}$

Figure 1 Structures of amycolatopsins A-C (1-3).

equivalents. Analysis of the 1D NMR $\left(\mathrm{MeOH}-d_{4}\right)$ data (Table 1 and Supplementary Table S1) revealed resonances for an ester/lactone carbonyl $\left(\delta_{C} 171.2\right)$, and 12 olefinic $\mathrm{sp}^{2}$ carbons $\left(\delta_{C}\right.$ 129.6-144.0), accounting for seven double bond equivalents and requiring that $\mathbf{1}$ incorporate five rings. Detailed analysis of $2 \mathrm{D}$ NMR $\left(\mathrm{MeOH}-d_{4}\right)$ data (Figure 2) revealed diagnostic correlations for a 20-membered macrocyclic lactone (C-1 to C-19) incorporating two triene moieties (C-2 to C-7, and C-10 to C-15), a pendant polysubstituted tetrahydropyran (C-20 to $\mathrm{C}-28)$ and three pyranose sugar residues $\left(\mathrm{C}-1^{\prime}\right.$ to C-6', C1" to C-6" and C-1"' to C-6"'). Double bond geometries $\left(E \Delta,{ }^{2,3} Z \Delta,{ }^{4,5} Z \Delta,{ }^{6,7} E \Delta,{ }^{8,9} E \Delta^{10,11}\right.$ and $\left.E \Delta^{12,13}\right)$ were assigned by consideration of diagnostic rotating-frame Overhauser effect spectroscopy (ROESY) correlations (Figure 2). The relative configuration of the tetrahydropyran moiety was established by ROESY correlations (Figure 2) that positioned $\mathrm{H}-23$ and $\mathrm{H}-25$ on the opposite face to $\mathrm{H}-22$ and H-20. Further consideration of a Newman projection and ROESY correlations from 20-Me to 22-OMe suggested the C-20 to C-21 relative configuration as indicated in Figure 2, whereas the axial configuration of $24-\mathrm{Me}$ was determined by comparison with the cometabolite 2, as shown in Figure 3. The relative configuration of the C- $1^{\prime}$ to C-6' pyranose was established by ROESY correlations from $\mathrm{H}-2^{\prime}$ to both $\mathrm{H}-\mathrm{1}^{\prime}$ and $\mathrm{H}-4^{\prime}$, and from $\mathrm{H}-4^{\prime}$ to $\mathrm{H}_{3}-6^{\prime}$, and from $J$-values that confirmed an equatorial orientation for $\mathrm{H}-1^{\prime}\left(J_{1^{\prime}, 2^{\prime}}\right.$ $3.8 \mathrm{~Hz})$, and axial orientations for $\mathrm{H}-2^{\prime}, \mathrm{H}-3^{\prime}, \mathrm{H}-4^{\prime}$ and $\mathrm{H}-5^{\prime}\left(J_{2^{\prime}}, 3^{\prime}\right.$ $9.7 \mathrm{~Hz}, J_{3^{\prime}, 4^{\prime}} 9.7 \mathrm{~Hz}$ and $J_{4^{\prime}, 5^{\prime}} 9.7 \mathrm{~Hz}$ ). The relative configuration of the C-1" to C-6" pyranose was established by ROESY correlations from 1,3-diaxial disposed $\mathrm{H}-1^{\prime \prime}$ and $\mathrm{H}-5^{\prime \prime}$, and from $J$-values that confirmed an equatorial orientation for $\mathrm{H}-3^{\prime \prime}\left(J_{3^{\prime \prime}}, 4^{\prime \prime} 2.8 \mathrm{~Hz}\right)$ and axial orientations for $\mathrm{H}-1^{\prime \prime}, \mathrm{H}-4^{\prime \prime}$ and $\mathrm{H}-5^{\prime \prime}\left(J_{1^{\prime \prime}, 2 \mathrm{a}^{\prime \prime}} 9.5 \mathrm{~Hz}\right.$ and $\left.J_{4^{\prime \prime}, 5^{\prime \prime}} 9.6 \mathrm{~Hz}\right)$. The relative configuration of the C- $1^{\prime \prime \prime}$ to C- 6 "' pyranose was established by ROESY correlations from 1,3-diaxial disposed H-5"' and both $\mathrm{H}-\mathrm{1}^{\prime \prime \prime}$ and $3^{\prime \prime \prime}-\mathrm{Me}$, and from $J$-values that confirmed axial orientations for H-1"', H-4 $4^{\prime \prime \prime}$ and H-5"' $\left(J_{1^{\prime \prime \prime}, 2 a^{\prime \prime \prime}} 9.9 \mathrm{~Hz}\right.$ and $\left.J_{4^{\prime \prime \prime}, 5^{\prime \prime \prime}} 9.6 \mathrm{~Hz}\right)$. As absolute configurations for the pyranose residues have not been determined, the structure for amycolatopsin A (1) is arbitrarily represented with D-hexose sugar configurations.

HRESI(+)MS analysis of 2 revealed a sodium adduct ion consistent with a molecular formula $\left(\mathrm{C}_{60} \mathrm{H}_{98} \mathrm{O}_{22}, \Delta \mathrm{mmu}-1.3\right)$ for a deoxy analog of 1 . This hypothesis was confirmed by comparison of the 1D $\operatorname{NMR}\left(\mathrm{MeOH}-d_{4}\right)$ data for $\mathbf{2}$ with $\mathbf{1}$ (Table 1 and Supplementary Tables S1 and S2) that revealed the only significant difference as conversion of the $6-\mathrm{CH}_{2} \mathrm{OH}$ moiety in $\mathbf{1}\left(\delta_{\mathrm{H}} 4.39\right.$ and $\left.4.49 ; \delta_{\mathrm{C}} 58.1\right)$ to a 6-Me moiety in $2\left(\delta_{\mathrm{H}} 2.06 ; \delta_{\mathrm{C}} 13.8\right)$. Detailed analysis of the $2 \mathrm{D}$ NMR data for 2 (Figure 3), applying the arguments outlined above for
1, permitted assignment of all double bond geometries, and relative configurations across C-20 to C-28, C-1' to C-6', C-1" to C-6" and $\mathrm{C}-1^{\prime \prime \prime}$ to C-6"'. Significantly, a ROESY correlation from $\mathrm{H}-25$ to $\mathrm{H}-1^{\prime \prime}$ in 2 established the axial orientation of $24-\mathrm{Me}$ that we also attribute to $\mathbf{1}$ on the basis of excellent NMR comparisons between $\mathbf{1}$ and $\mathbf{2}$ (see above).

HRESI(+)MS analysis of 3 revealed a sodium adduct ion consistent with a molecular formula $\left(\mathrm{C}_{47} \mathrm{H}_{75} \mathrm{O}_{17} \Delta \mathrm{mmu}-0.3\right)$ for an aglycone analog of $\mathbf{1}$. Comparison of the $1 \mathrm{D}$ NMR $\left(\mathrm{MeOH}-d_{4}\right)$ data for 3 with 1 (Table 1 and Supplementary Tables S1 and S3) revealed significant differences attributed to hydrolysis of the C-24 disaccharide residue. Detailed analysis of the 2D NMR data for 3 (Figure 4), applying the arguments outlined above for $\mathbf{1}$, permitted assignment of all double bond geometries, and relative configurations across C-20 to C-28 and C-1' to C-6'.

In our hands, $1-3$ did not inhibit growth $\left(\mathrm{IC}_{50}>30 \mu \mathrm{M}\right)$ of the Gram-positive bacteria Bacillus subtilis (ATCC 6633) and Staphylococcus aureus (ATCC 25923), the Gram-negative bacteria Escherichia coli (ATCC 25922) and Pseudomonas aeruginosa (ATCC 27853), or the fungus Candida albicans (ATCC 90028) (Table 2 and Supplementary Figure S11). In comparison, 1 and 3 inhibited growth of $M$. bovis (BCG, $\mathrm{IC}_{50} 0.4$ and $2.7 \mu \mathrm{M}$ ) and M. tuberculosis (H37Rv, $\mathrm{IC}_{50} 4.4$ and $5.7 \mu \mathrm{M}$ ) in liquid culture (Table 2). It is also noteworthy that $\mathbf{1}$ and 2 exhibited significant cytotoxicity toward human colon (SW620, $\mathrm{IC}_{50} 0.08$ and $\left.0.14 \mu \mathrm{M}\right)$ and lung $\left(\mathrm{NCIH}-460, \mathrm{IC}_{50} 1.2\right.$ and $\left.0.28 \mu \mathrm{M}\right)$ carcinoma cells, whereas the aglycone 3 was 5- to 100-fold less cytotoxic ( $\mathrm{IC}_{50} 10$ and $5.9 \mu \mathrm{M}$ ) (Table 2 and Supplementary Figure S12).

The amycolatopsins A-C (1-3) are new examples of a rare class of glycosylated polyketide macrolides, structurally and biosynthetically related to the apoptolidins reported from Amycolatopsis ${ }^{14,15}$ and Nocardiopsis ${ }^{4,8-10}$ spp., and ammocidins reported from Saccharothrix $\mathrm{sp}^{5-7}$ The amycolatopsins share a common macrolide scaffold with the apoptolidins and ammocidins, and combine other unique structure features from both. For example, amycolatopsins share 4'-O-methylation with apoptolidins, ${ }^{4,8-10,14,15}$ and 25-methoxypropyl and 20-methyl moieties with ammocidins. ${ }^{5-7}$ With respect to the latter, our suggested assignment of configurations about the C-20 to C-25 moiety in 1-3 provides a basis for making similar assignments in all known ammocidins (where these configurations are currently unassigned).$^{5-7}$ Although neither absolute nor relative configurations have been assigned to chiral centers within the macrolactone ring system of any known ammocidins, in 1998 NOESY correlations were used to assign absolute configurations about comparable centers in the 
Table $1{ }^{1} \mathrm{H}(600 \mathrm{MHz})$ and ${ }^{13} \mathrm{C}(150 \mathrm{MHz})$ NMR data for $1-3$ in $\mathrm{MeOH}-d_{4}$

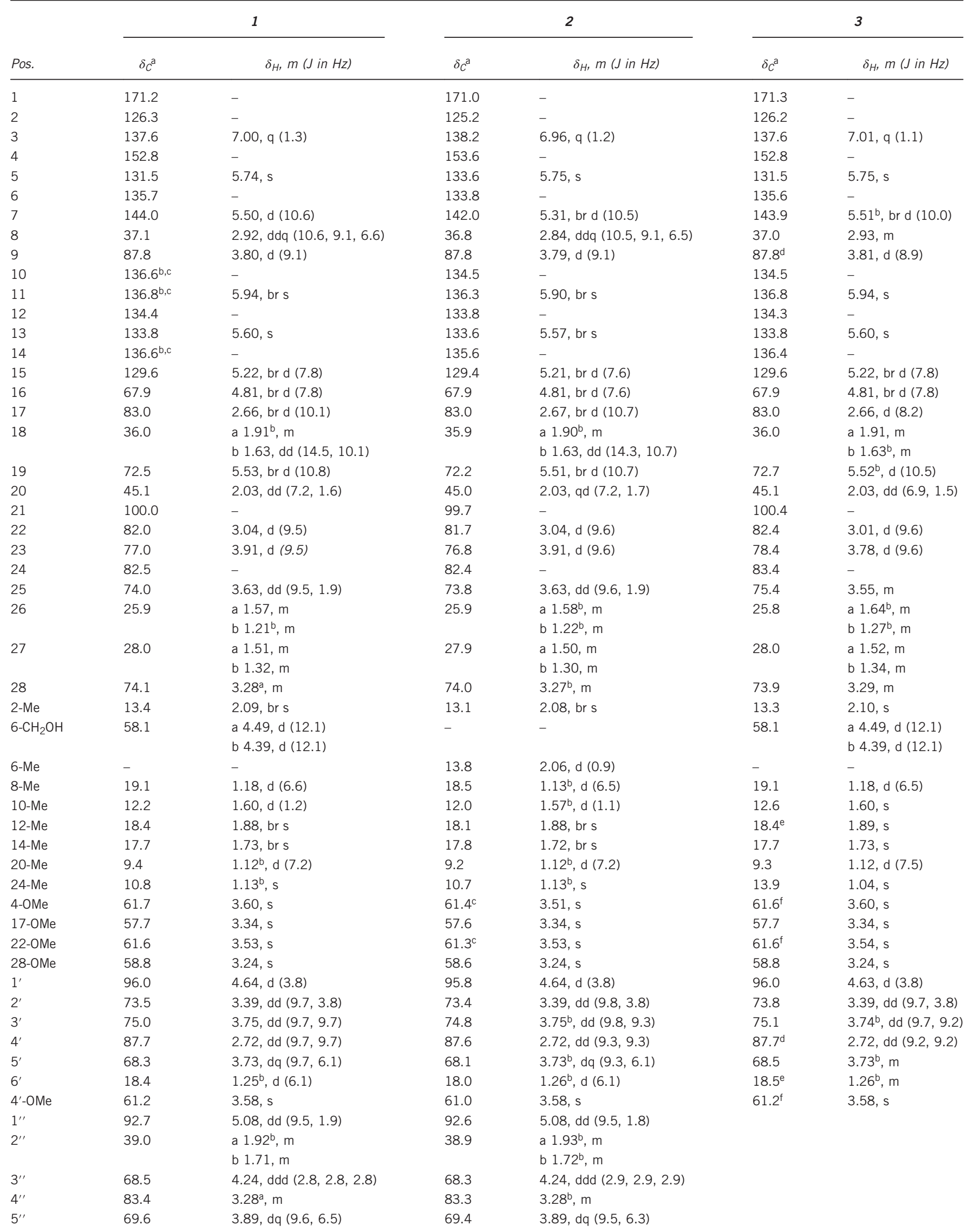




\begin{tabular}{|c|c|c|c|c|c|c|}
\hline \multirow[b]{2}{*}{ Pos. } & \multicolumn{2}{|r|}{1} & \multicolumn{2}{|r|}{2} & \multicolumn{2}{|c|}{3} \\
\hline & $\delta_{C^{a}}$ & $\delta_{H}, m(J$ in $H z)$ & $\delta_{C}{ }^{a}$ & $\delta_{H}, m(J$ in $H z)$ & $\delta_{C}{ }^{a}$ & $\delta_{H}, m(J$ in $\mathrm{Hz})$ \\
\hline $1^{\prime \prime \prime}$ & 102.0 & $4.69, \mathrm{dd}(9.9,1.9)$ & 101.9 & $4.69, \mathrm{dd}(9.8,1.9)$ & & \\
\hline $2^{\prime \prime \prime}$ & 46.7 & $1.93^{b}, \mathrm{~m}$ & 46.7 & a $1.93^{b}, \mathrm{~m}$ & & \\
\hline & & $1.70, \mathrm{~m}$ & & b $1.70^{\mathrm{b}}, \mathrm{m}$ & & \\
\hline $4^{\prime \prime \prime}$ & 80.3 & 3.09, d (9.6) & 80.1 & $3.09, d(9.5)$ & & \\
\hline $5^{\prime \prime \prime}$ & 72.5 & $3.37, \mathrm{dq}(9.6,6.0)$ & $72.5^{c}$ & $3.37, \mathrm{dq}(9.5,6.1)$ & & \\
\hline $6^{\prime \prime \prime}$ & 19.1 & $1.27^{b}, d(6.0)$ & 19.5 & $1.26^{b}, d(6.1)$ & & \\
\hline $3^{\prime \prime \prime}-\mathrm{Me}$ & 20.5 & $1.24^{\mathrm{b}}, \mathrm{s}$ & 18.5 & $1.23^{\mathrm{b}}, \mathrm{s}$ & & \\
\hline
\end{tabular}

aAssignments supported by 2D heteronuclear single quantum correlation (HSQC) and heteronuclear multiple bond correlation (HMBC) experiments.

boverlapping resonances.

${ }^{c-f}$ Signals are interchangeable within the same letter.

Table 2 In vitro antimicrobial and cytotoxic activities of 1-3

\begin{tabular}{lccc}
\hline & \multicolumn{3}{c}{$/ C_{50}(\mu)^{\mathrm{a}}$} \\
\cline { 2 - 4 } Cells & $\mathbf{1}$ & $\mathbf{2}$ & $\mathbf{3}$ \\
\hline M. bovis (BCG) & 0.4 & $>30$ & 2.7 \\
M. tuberculosis (H37Rv) & 4.4 & $>30$ & 5.7 \\
B. subtilis (ATCC 6633) & $>30$ & $>30$ & $>30$ \\
S. aureus (ATCC 25923) & $>30$ & $>30$ & $>30$ \\
E. coli (ATCC 25922) & $>30$ & $>30$ & $>30$ \\
P. aeruginosa (ATCC 27853) & $>30$ & $>30$ & $>30$ \\
C. albicans ATCC 90028 & $>30$ & $>30$ & $>30$ \\
NCIH-460 & 1.2 & 0.28 & 5.9 \\
SW620 & 0.08 & 0.14 & 10 \\
\hline
\end{tabular}

${ }^{\mathrm{a}} \mathrm{C}_{50} \mu \mathrm{m}$ are from two independent cultures.

closely related apoptolidin. ${ }^{11}$ Subsequent researchers extrapolated these assignments, and applied them to all other known examples of the apoptolidin structure class. ${ }^{4,8-10,12,14,15}$ To the best of our knowledge there are no published validations of these assignments that, in our view, remain tentative at best. In the case of the amycolatopsins, careful analysis of ROESY data revealed evidence of macrolactone conformational flexibility, cautioning against the use of such approaches to configurational assignment. For example, in the case of amycolatopsin B and C we observed ROESY correlations between 2-Me and $\mathrm{H}-5$, and between $3-\mathrm{H}$ and $\mathrm{H}-5$, suggestive of rotation flexibility about the 3-4 bond. Erring on the side of caution, configurations about C-8, C-9, C-16, C-17 and C-19 in 1-3 remain unassigned. Our preliminary structure activity relationship analysis of amycolatopsins revealed noteworthy correlations. First, the aglycone 3 exhibits comparatively lower mammalian cytotoxicity than the corresponding disaccharride glycosides $\mathbf{1}$ and 2 , consistent with literature reports where the aglycone apoptolidin F exhibits reduced cytotoxicity compared with all other known disaccharride glycoside apoptolidins. ${ }^{13}$ Second, and arguably of greater importance, the antimycobacterial activity of amycolatopsins correlate strongly with hydroxylation of the 6-Me (that is, $\mathbf{1}$ and 3), a site of hydroxylation not previously observed among apoptolidins or ammocidins. Our observations on the amycolatopsins are encouraging in that they suggest a strategy (selective hydroxylation and glycoside hydrolysis) for enhancing antimycobacterial activity across this class of polyketide macrolide.

\section{METHODS}

\section{General experimental procedures}

Chiroptical measurements $\left([\alpha]_{\mathrm{D}}\right)$ were obtained on a JASCO P-1010 polarimeter (Tokyo, Japan) in a $100 \times 2 \mathrm{~mm}$ cell at $22^{\circ} \mathrm{C}$. UV-visible spectra were obtained on a Varian Cary 50 UV-visible spectrophotometer (Santa Clara, CA, USA )with $1 \mathrm{~cm}$ pathway quartz cells. NMR spectra were obtained on a Bruker Avance DRX600 spectrometer (Billerica, MA, USA) in the solvents indicated and referenced to residual signals $\left(\delta_{\mathrm{H}} 3.31\right.$ and $\left.\delta_{\mathrm{C}} 49.1 \mathrm{ppm}\right)$ in deuterated solvents. ESIMS were acquired using Agilent 1100 Series separations module equipped with an Agilent 1100 Series LC/MS mass detector (Santa Clara, CA, USA) in both positive and negative ion modes under the following LC conditions using Zorbax SB-C $5 \mu \mathrm{m}$ column, $150 \times 4.6 \mathrm{~mm}$, eluting with $1.0 \mathrm{ml} \mathrm{min}^{-1} 90 \% \mathrm{H}_{2} \mathrm{O} / \mathrm{MeCN}$ to $100 \% \mathrm{MeCN}$, and an isocratic $0.05 \%$ $\mathrm{HCO}_{2} \mathrm{H}$ modifier over $15 \mathrm{~min}$, with detection at 210 and $254 \mathrm{~nm}$. HRESIMS measurements were obtained on a Bruker micrOTOF mass spectrometer by direct infusion in $\mathrm{MeCN}$ at $3 \mu \mathrm{lmin} \mathrm{m}^{-1}$ using sodium formate clusters as an internal calibrant. Analytical HPLC-DAD was performed on a gradient Shimadzu HPLC system comprising a LC-10AT VP gradient chromatograph, SPD-M10A VP DAD and SCL-10A VP system controller. Preparative HPLC was performed on a gradient Shimadzu HPLC system (Sydney, Australia) comprising two LC-8A preparative liquid pumps with a static mixer, SPDM10AVP diode array detector and SCL-10AVP system controller with a standard Rheodyne injection port. All solvents were HPLC grade.

\section{Isolation and identification of Amycolatopsis sp. MST-108494}

The strain was isolated from a soil sample (Soil no. 3019) collected in timbered country near Woolshed Flat, $15 \mathrm{~km}$ north of Port Augusta, South Australia, in 1996. The soil sample was red brown in color, with low levels of organic matter and salinity (106 ppm) and of neutral pH (6.6). A subsample of soil (20 g) was treated with sterile $\mathrm{H}_{2} \mathrm{O}(100 \mathrm{ml})$, and $10^{-3}$ and $10^{-4}$ dilutions plated on ISP2 agar and incubated for 7 days at $28^{\circ} \mathrm{C}$. Single colonies were transferred to ISP2 agar isolation plates that were incubated at $28^{\circ} \mathrm{C}$ for $2-3$ weeks. The pure strain of MST-108494 was accessioned and preserved at $-80^{\circ} \mathrm{C}$ in $20 \%$ aqueous glycerol. $\mathrm{MeOH}$ extracts prepared from residual agar $\left(1 \mathrm{ml} \mathrm{g}^{-1}\right.$ agar $)$ were used for chemical and biological profiling. Cells from an isolated colony on a 3-day ISP2 agar plate were sampled and suspended in PrepMan Ultra Sample Preparation Reagent (Sydney, Australia) $(100 \mu \mathrm{l})$. The sample was boiled at $100{ }^{\circ} \mathrm{C}$ for $10 \mathrm{~min}$ and the recovered 16S rRNA sequenced at the Australian Genome Research Facility (AGRF, Sydney, Australia), and registered in the NCBI (National Center for Biotechnology Information) GenBank database with accession number MF102107. The gene sequence is provided in the Supplementary Information.

\section{Media optimization and co-metabolite profiling}

Amycolatopsis sp. MST-108494 was cultured on a range of agar, liquid and grain media. Agar media ( $15 \mathrm{ml}$ ) were prepared from yeast glucose malt agar (I2A), I2A+starch (GYA), I2A+mannitol (IMA), modified Bennetts agar (MSA), soy 


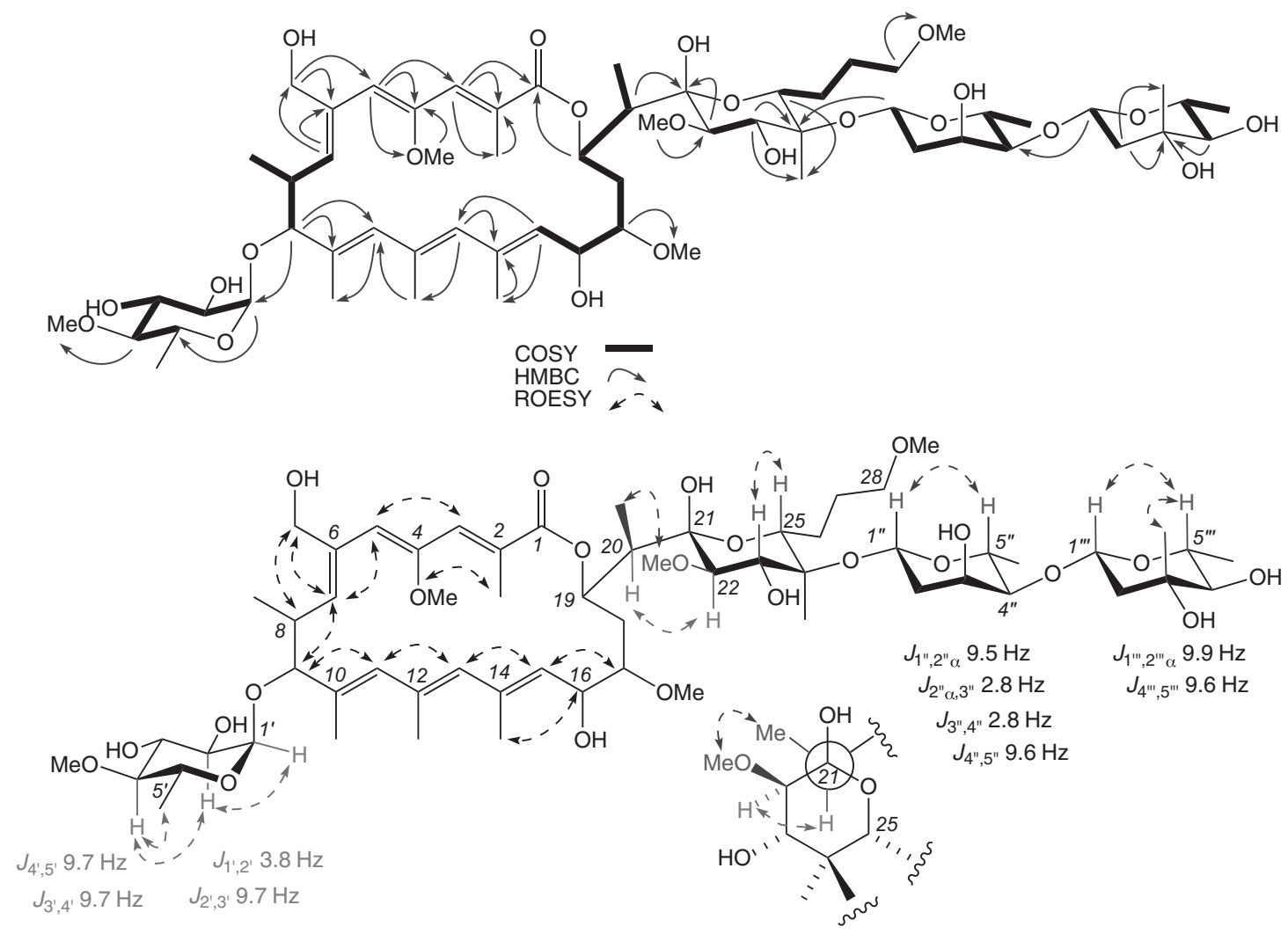

C-21 to C-20 Newman projection

Figure 2 Diagnostic 2D NMR $\left(\mathrm{MeOH}-d_{4}\right)$ correlations for 1 . A full color version of this figure is available at Journal of Antibiotics online.

and beef extract agar (LUA), yeast, molasses and peptone agar (MOA) and casein glycerol agar $(\mathrm{CGA})$. Liquid media $(50 \mathrm{ml})$ were prepared from these same media with the omission of $2.0 \%$ bacteriological agar (that is, I2L, GYL, IML, MSL, LUL and CGL) in single baffled Erlenmeyer flasks (250 ml). Grains media $(50 \mathrm{~g})$ (that is, barley $(\mathrm{PB})$, wheat $(\mathrm{BL})$, jasmine rice $(\mathrm{JR})$ and basmati rice (BS)) in $\mathrm{H}_{2} \mathrm{O}(30 \mathrm{ml})$ were prepared in Erlenmeyer flasks $(250 \mathrm{ml})$. Sterilized agar, liquid and grain media were inoculated with a spore suspension of MST-108494 prepared from a 7-day, $28^{\circ} \mathrm{C}$, I2A agar plate. Subsamples $(\sim 1 \mathrm{~g})$ recovered from each cultivation on days 7 and 10 were extracted with $\mathrm{MeOH}(2 \mathrm{ml})$, centrifuged $(15700 \mathrm{~g}$ for $3 \mathrm{~min})$ and the supernatant analyzed by HPLC-DAD (Alltima C18 'rocket' column, $100 \AA, 53 \times 7 \mathrm{~mm}, 3 \mu \mathrm{m}$, eluted with a $3 \mathrm{ml} \mathrm{min}^{-1}$ gradient from $90 \% \mathrm{H}_{2} \mathrm{O} / \mathrm{MeCN}$ to $100 \% \mathrm{MeCN}$, over $7 \mathrm{~min}$, with an isocratic $0.01 \%$ TFA modifier and a $2 \mathrm{~min}$ hold). The resulting co-metabolite retention time and UV-visible (DAD) spectra were accessioned into the Microbial Screening Technologies (Sydney, Australia) database (COMET), and dereplicated against 5000 microbial metabolites and the cometabolite profiles of $>2500$ strains of known species, patented strains and metabolically rich actinomycetes species isolated from solid samples. Identification of likely replicate cultures was undertaken against a database of 300000 actinomycete cultures isolated at MST. ${ }^{16}$

\section{Preparative cultivation and purification}

A spore suspension of Amycolatopsis sp. MST-108494 (100 $\mu \mathrm{l})$ applied to LUA plates $(200 \times 15 \mathrm{ml})$ was incubated at $28^{\circ} \mathrm{C}$ for 14 days. The combined agar $(2.5 \mathrm{~kg})$ was extracted with acetone $(2 \times 2.8 \mathrm{l})$ for $2 \mathrm{~h}$ on a rotatory platform (150 r.p.m.) and then concentrated in vacuo to an aqueous residue (2.2 l, $24.7 \mathrm{~g})$. The aqueous residue was applied to two $\mathrm{C}_{18}$ columns $(2 \times 10 \mathrm{~g})$, washed with deionized $\mathrm{H}_{2} \mathrm{O}$ and the bound metabolites eluted with $\mathrm{MeCN}$ $(2 \times 40 \mathrm{ml})$ and concentrated in vacuo to an organic extract $(2.28 \mathrm{~g})$. A portion of the extract $(1.0 \mathrm{~g})$ was dissolved in $\mathrm{MeCN}(4 \mathrm{ml})$ and fractionated by preparative HPLC (Platinum EPS $\mathrm{C}_{18}$, gradient 30 to $60 \% \mathrm{MeCN} / \mathrm{H}_{2} \mathrm{O}$ over $20 \mathrm{~min}$, with a step to $100 \% \mathrm{MeCN}$ over $10 \mathrm{~min}$ ) to yield amycolatopsin A (1)
( $t_{\mathrm{R}} 14.9 \mathrm{~min}, 7.3 \%$ ) and amycolatopsin B (2) ( $t_{\mathrm{R}} 19.3 \mathrm{~min}, 3.5 \%$ ). A second fermentation was undertaken using GYA agar and processed as described above to yield an extract $(0.57 \mathrm{~g})$. The extract was dissolved in $\mathrm{MeCN}(4 \mathrm{ml})$ and fractionated by preparative HPLC (Platinum EPS $\mathrm{C}_{18}$, isocratic conditions $45 \%$ $\mathrm{MeCN} / \mathrm{H}_{2} \mathrm{O}$ over $20 \mathrm{~min}$, with a step to $100 \% \mathrm{MeCN}$ over $10 \mathrm{~min}$ ) to yield amycolatopsin C (3) ( $\left.t_{\mathrm{R}} 11.0 \mathrm{~min}, 1.6 \%\right)$ and (1) ( $\left.t_{\mathrm{R}} 15.1 \mathrm{~min}, 6.1 \%\right)$ (note that $\%$ yields were determined on a mass-to-mass basis against the organic extract).

Amycolatopsin A (1): white powder; $[\alpha]^{21}{ }_{\mathrm{D}}-41(c 0.06, \mathrm{MeOH}) ; \mathrm{UV}(\mathrm{MeOH})$ $\lambda_{\max }(\log \varepsilon): 248$ (3.49), 276 (3.38), $320(2.96) \mathrm{nm}$, Supplementary Figure $S 5 ;{ }^{1} \mathrm{H}$ NMR $\left(600 \mathrm{MHz}, \mathrm{MeOH}-d_{4}\right)$, Table 1 and Supplementary Figure S4; HRESI $(+)$ MS m/z $1209.6380[\mathrm{M}+\mathrm{Na}]^{+}$(calcd for $\mathrm{C}_{60} \mathrm{H}_{98} \mathrm{O}_{23} \mathrm{Na}, 1209.6391$ ).

Amycolatopsin B (2): white powder; $[\alpha]^{21} \mathrm{D}-40$ (c 0.05, MeOH); UV $(\mathrm{MeOH}) \lambda_{\max }(\log \varepsilon): 268$ (3.59), 325 (3.15) nm, Supplementary Figure S7; ${ }^{1} \mathrm{H}$ NMR $\left(600 \mathrm{MHz}, \mathrm{MeOH}-d_{4}\right)$, Table 1 and Supplementary Figure S6; HRESI (+)MS m/z 1193.6455 [M+Na $]^{+}$(calcd for $\mathrm{C}_{60} \mathrm{H}_{98} \mathrm{O}_{22} \mathrm{Na}, 1193.6442$ ).

Amycolatopsin C (3): white powder; $[\alpha]^{21}{ }_{\mathrm{D}}-15(c 0.06, \mathrm{MeOH}) ; \mathrm{UV}(\mathrm{MeOH})$ $\lambda_{\max }(\log \varepsilon): 271(3.60), 313(3.49) \mathrm{nm}$, Supplementary Figure S9; ${ }^{1} \mathrm{H}$ NMR $\left(600 \mathrm{MHz}, \mathrm{MeOH}-d_{4}\right)$, Table 1 and Supplementary Figure S8; HRESI(+)MS m/z $935.4978[\mathrm{M}+\mathrm{Na}]^{+}$(calcd for $\left.\mathrm{C}_{47} \mathrm{H}_{76} \mathrm{O}_{17} \mathrm{Na}, 935.4975\right)$.

\section{Antibacterial and antifungal assays}

The bacteria and the fungus to be tested were streaked onto a tryptic soy agar plate and incubated at $37^{\circ} \mathrm{C}$ for $24 \mathrm{~h}$ and $26.5^{\circ} \mathrm{C}$ for $48 \mathrm{~h}$, respectively. One colony was then transferred to fresh tryptic soy broth $(15 \mathrm{ml})$ and the cell density was adjusted to $10^{4}-10^{5}$ CFUs per $\mathrm{ml}$ to OD 0.1 . Amycolatopsins A-C (1-3) were dissolved in DMSO and diluted with $\mathrm{H}_{2} \mathrm{O}$ to give $300 \mu \mathrm{m}$ stock solutions (10\% DMSO). The stock solutions were then serially diluted with $10 \%$ DMSO. An aliquot $(20 \mu \mathrm{l})$ of each dilution was transferred to a $96-$ well microtiter plate and freshly prepared microbial broth $(180 \mu \mathrm{l})$ was added to each well to give final concentration of 30 to $0.01 \mu \mathrm{M}$ in $1 \%$ DMSO. The plates were incubated at $37^{\circ} \mathrm{C}$ for $24 \mathrm{~h}$ and the optical density of each well was measured spectrophotometrically at $600 \mathrm{~nm}$ (POLARstar Omega plate reader, 


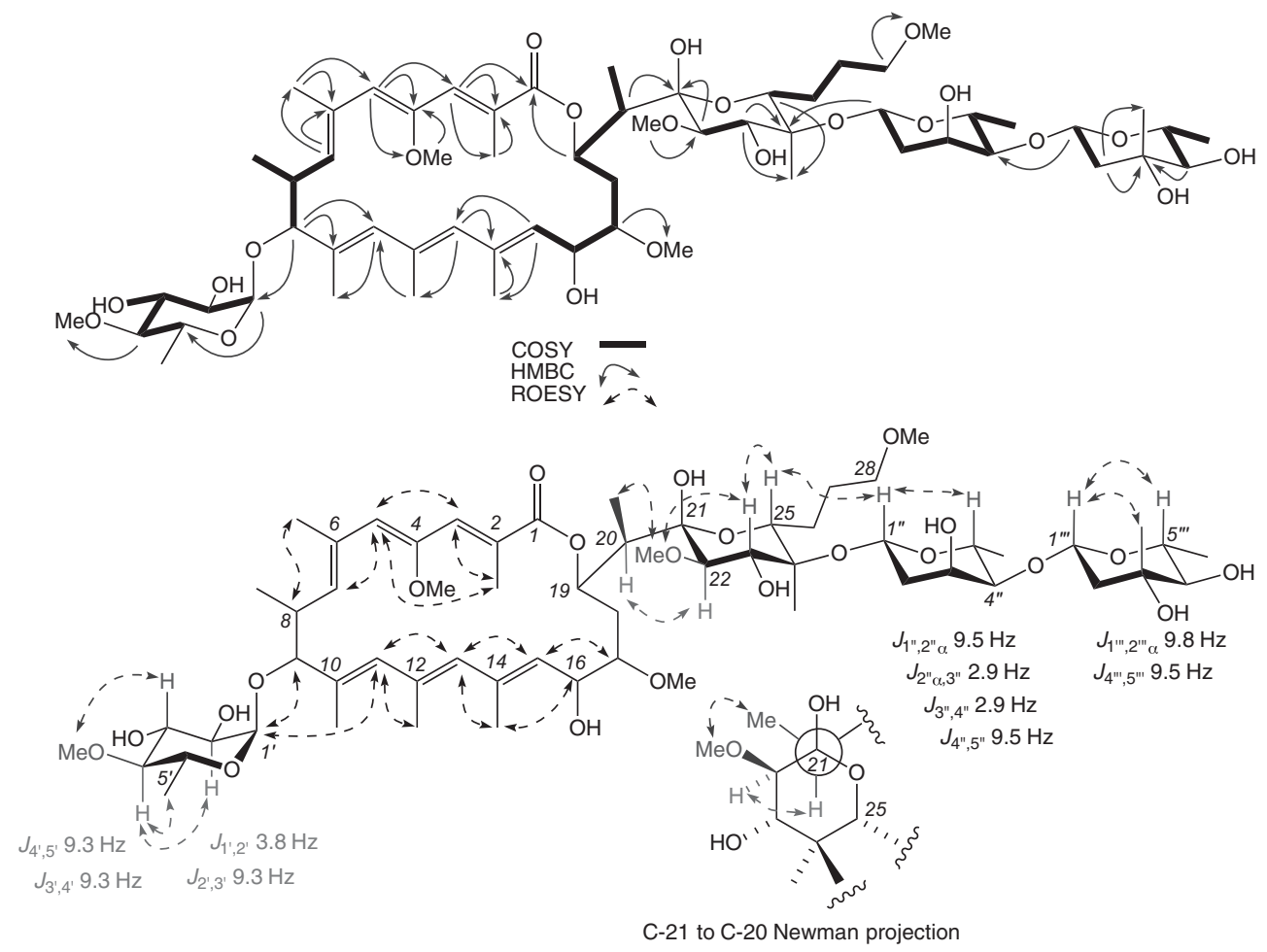

Figure 3 Key 2D NMR ( $\left.\mathrm{MeOH}-d_{4}\right)$ correlations and residues for amycolatopsin B (2). A full color version of this figure is available at Journal of Antibiotics online.
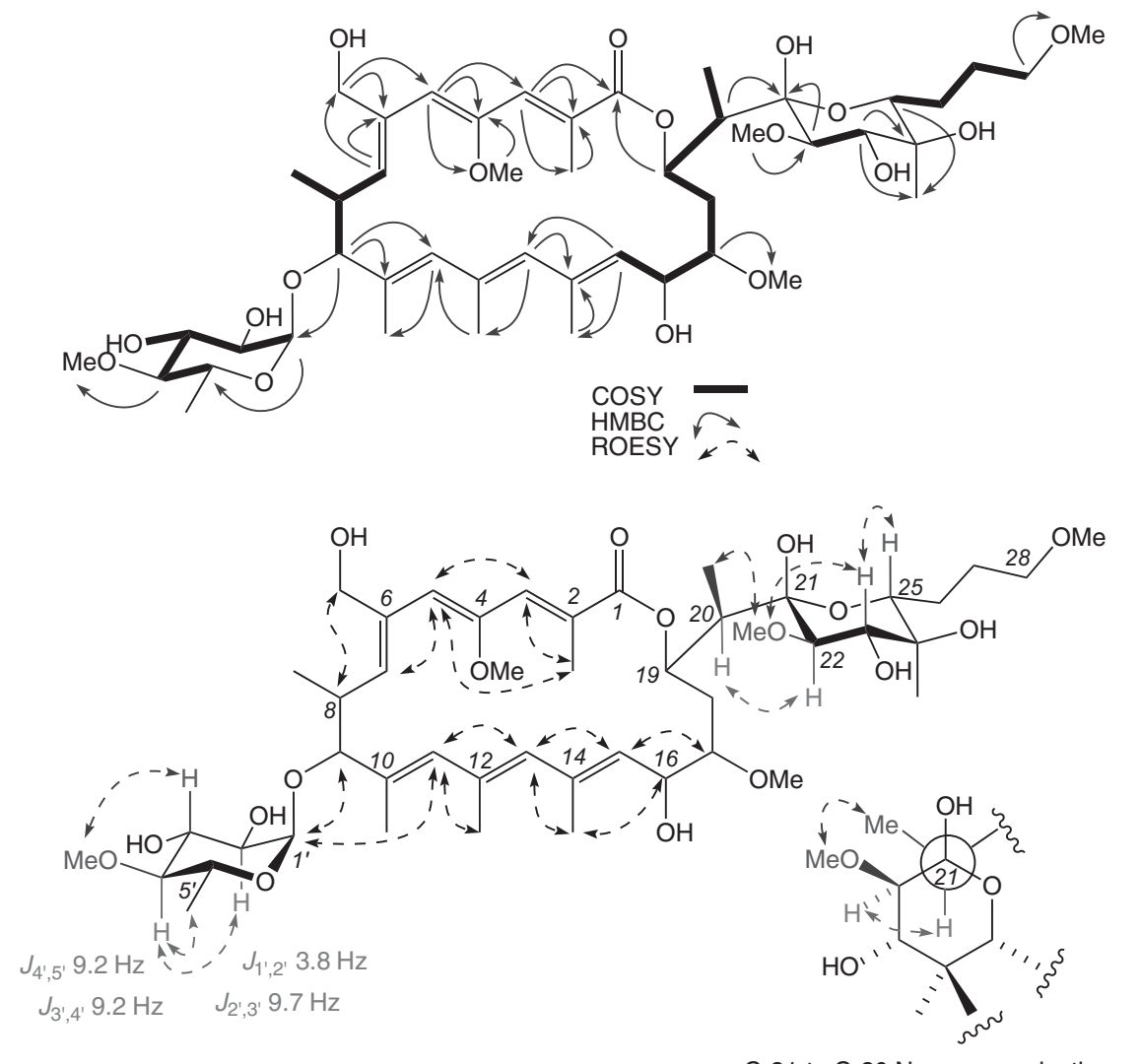

Figure 4 Key 2D NMR ( $\left.\mathrm{MeOH}-d_{4}\right)$ correlations and residues for amycolatopsin C (3). A full color version of this figure is available at Journal of Antibiotics online. 
BMG LABTECH, Offenburg, Germany). Each test compound was screened against the Gram-negative bacteria $E$. coli (ATCC 11775) and $P$. aeruginosa (ATCC 10145), the Gram-positive bacteria S. aureus (ATCC 9144 and ATCC 25923), B. subtilis (ATCC 6633 and ATCC 6051) and C. albicans (ATCC 90028). The $\mathrm{IC}_{50}$ value was calculated as the concentration of the compound or antibiotic required for $50 \%$ inhibition of the bacterial and/or fungal growth.

\section{Antimycobacterial assays}

M. bovis, Bacille Calmette Guerin (BCG) and M. tuberculosis (H37Rv) were grown until early-mid log phase in $7 \mathrm{H} 9$ liquid medium (Difco, Brisbane, Australia) containing $0.2 \%$ glycerol, $0.05 \%$ Tween- $80,5 \%$ bovine serum albumin, $2 \%$ dextrose and $0.85 \%$ sodium chloride and then diluted in complete $7 \mathrm{H} 9$ medium to an $\mathrm{OD}(600 \mathrm{~nm})$ of 0.02 . Amycolatopsins A-C (1-3) were dissolved in DMSO and diluted with $\mathrm{H}_{2} \mathrm{O}$ to give a $600 \mu \mathrm{M}$ stock solution in 10\% DMSO. The stock solution was then serially diluted with $10 \%$ DMSO and an aliquot of $10 \mu \mathrm{l}$ of each dilution was transferred to wells of a 96-well microtiter plate together with $190 \mu \mathrm{l}$ of bacterial suspension, resulting in final concentrations of 30 to $0.01 \mu \mathrm{M}$ in $1 \%$ DMSO. Bacterial growth at $37^{\circ} \mathrm{C}$ in the presence of amycolatopsins (1-3) was monitored by OD measurements over 7 days. Isoniazid (INH, $20 \mu \mathrm{g} \mathrm{ml}^{-1}$ in $\mathrm{H}_{2} \mathrm{O}$ ) and DMSO served as positive and negative controls.

\section{Cytotoxicity assays}

The MTT (3-(4,5-dimethylthiazol-2-yl)-2,5-diphenyltetrazolium bromide) assay was modified from that previously described ${ }^{17,18}$ using adherent cell lines SW620 and NCIH-460. SW620 and NCIH-460 were cultured in RPMI medium 1640 as adherent monolayer in flasks supplemented with $10 \%$ fetal bovine serum, $2 \mathrm{~mm}$ L-glutamine, 100 unit $\mathrm{ml}^{-1}$ penicillin and $100 \mu \mathrm{g} \mathrm{ml}^{-1}$ streptomycin in a humidified $37^{\circ} \mathrm{C}$ incubator supplied with $5 \% \mathrm{CO}_{2}$. Cells were harvested with trypsin and dispensed into 96-well microtiter assay plates at 2000 cells per well for SW620, and 5000 cells per well for NCIH-460, then incubated for $18 \mathrm{~h}$ at $37^{\circ}$ $\mathrm{C}$ with $5 \% \mathrm{CO}_{2}$. Amycolatopsins A-C (1-3) were dissolved in 5\% DMSO in phosphate-buffered saline $(\mathrm{v} / \mathrm{v})$ and aliquots $(20 \mu \mathrm{l})$ tested over a series of final concentrations ranging from $10 \mathrm{~nm}$ to $30 \mu \mathrm{M}$. Control wells were treated with $5 \%$ aqueous DMSO. After $68 \mathrm{~h}$ of incubation at $37^{\circ} \mathrm{C}$ with $5 \% \mathrm{CO}_{2}$ an aliquot $(20 \mu \mathrm{l})$ of MTT in phosphate-buffered saline was added to each well (final concentration of $0.4 \mathrm{mg} \mathrm{ml}^{-1}$ ), and the microtiter plates incubated for a further $4 \mathrm{~h}$ at $37^{\circ} \mathrm{C}$ with $5 \% \mathrm{CO}_{2}$. Medium was aspirated and precipitated formazan crystals dissolved in DMSO (100 $\mu$ l per well). The absorbance of each well was measured at $580 \mathrm{~nm}$ (PowerWave XS Microplate Reader, Bio-Tek Instruments, Winooski, VT, USA). $\mathrm{IC}_{50}$ values were calculated as the concentration of analyte required for $50 \%$ inhibition of cell growth (compared with negative controls). Vinblastine $\left(20 \mu \mathrm{g} \mathrm{ml}^{-1}\right.$ in $5 \%$ DMSO) and DMSO served as positive and negative controls, respectively. All experiments were performed in duplicate.

\section{CONFLICT OF INTEREST}

The authors declare no conflict of interest.

\section{ACKNOWLEDGEMENTS}

We thank AE Lacey (MST) for assistance with the metabolite purification. We acknowledge support from the University of Queensland Institute for
Molecular Bioscience and University of Queensland Diamantina Institute. This research was funded in part by The University of Queensland (UQECR1607045).

Author contributions: EL, AC and DV were responsible for the cultivation and isolation of amycolatopsins. ZGK acquired, tabulated and interpreted all spectroscopic data, carried out all bioassays and assembled the Supplementary Information. AAS reviewed all NMR data. AB had oversight of all mycobacterial studies. RJC initiated the research program, and had oversight of all chemical studies and drafting of the manuscript. All authors have given approval to the final version of the manuscript.

1 Garcia, A., Bocanegra-Garcia, V., Palma-Nicolas, J. P. \& Rivera, G. Recent advances in antitubercular natural products. Eur. J. Med. Chem. 49, 1-23 (2012).

2 World Health Organisation WHO treatment guidelines for drug- resistant tuberculosis, 2016 (ISBN 978924154963 9).

3 Stop TB Partnership. The Global Plan to Stop TB, 2006-2015. actions for life: towards a world free of tuberculosis. Int. J. Tuberc. Lung Dis. 10 240-241 (2006).

4 Kim, J. W., Adachi, H., Shin-Ya, K., Hayakawa, Y. \& Seto, H. Apoptolidin, a new apoptosis inducer in transformed cells from Nocardiopsis sp. J. Antibiot. 50, 628-630 (1997).

5 Murakami, R. et al. Ammocidins B, C and D, new cytotoxic 20-membered macrolides from Saccharothrix sp. AJ9571. J. Antibiot. 62, 123-127 (2009).

6 Murakami, R. et al. Ammocidin, a new apoptosis inducer in Ras-dependent cells from Saccharothrix sp. I. Production, isolation and biological activity. J. Antibiot. 54, 710-713 (2001).

7 Murakami, R. et al. Ammocidin, a new apoptosis inducer in Ras-dependent cells from Saccharothrix sp. II. Physico-chemical properties and structure elucidation. J. Antibiot. 54, 714-717 (2001).

8 Wender, P. A., Sukopp, M. \& Longcore, K. Apoptolidins B and C: isolation, structure determination, and biological activity. Org. Lett. 7, 3025-3028 (2005).

9 Wender, P. A. \& Longcore, K. E. Apoptolidins E and F, new glycosylated macrolactones isolated from Nocardiopsis sp. Org. Lett. 11, 5474-5477 (2009).

10 Wender, P. A. \& Longcore, K. E. Isolation, structure determination, and anti-cancer activity of apoptolidin D. Org. Lett. 9, 691-694 (2007).

11 Hayakawa, Y., Kim, J. W., Adachi, H., Shin-ya, K., Fujita, K. \& Seto, H. Structure of apoptolidin, a specific apoptosis inducer in transformed Cells. J. Am. Chem. Soc. 120, 3524-3525 (1998).

12 Wender, P. A., Gulledge, A. V., Jankowski, O. D. \& Seto, H. Isoapoptolidin: structure and activity of the ring-expanded isomer of apoptolidin. Org. Lett. 4 3819-3822 (2002).

13 Chau, S. T. Sulikowski, G. A. \& Wu, B. Studies on the synthesis of the apoptolidins. Strategies and Tactics in Organic Synthesis 8, 375-394 (2012).

14 Sheng, Y. et al. Succinylated apoptolidins from Amycolatopsis sp. ICBB 8242. Org. Lett. 17, 2526-2529 (2015).

15 Serrill, J. D. et al. Apoptolidins A and C activate AMPK in metabolically sensitive cell types and are mechanistically distinct from oligomycin A. Biochem. Pharmacol. 93, 251-265 (2015).

16 Lacey, E. \& Tennant, S. Secondary metabolites - the focus of biodiscovery and perhaps the key to unlocking new depths in taxonomy. Microbiol. Aust. 24, 34-35 (2003).

17 Carmichael, J., DeGraff, W. G., Gazdar, A. F., Minna, J. D. \& Mitchell, J. B. Evaluation of a tetrazolium-based semiautomated colorimetric assay: assessment of chemosensitivity testing. Cancer Res. 47, 936-942 (1987).

18 Henrich, C. J. et al. A high-throughput cell-based assay for inhibitors of ABCG2 activity. J. Biomol. Screen. 11, 176-183 (2006).

Supplementary Information accompanies the paper on The Journal of Antibiotics website (http://www.nature.com/ja) 